\title{
Effectiveness of geropsychiatric home treatment concerning parameters of physical health: matched-pair study
}

Christa Peinhaupt, Gernot Fassolder, Wolfgang Habacher, Monika Singer, Gerhard Hermann and Günter Klug

\section{Background}

There is evidence of the effectiveness of multi-professional home treatment models with regards to improving mental health for elderly patients with mental illness. However, there is a lack of studies examining the efficacy with regard to physical health.

\section{Aims}

To explore the effectiveness of geropsychiatric home treatment for elderly patients with mental illness with regards to improving physical health by assessing the need of physical treatment.

\section{Method}

A 1-year retrospective matched-pair cohort study was conducted in four regions of Austria. We compared 91 patients with a broad spectrum of mental disorders in geropsychiatric home treatment by 1:2 matching to 182 patients in treatment as usual regarding number of contacts with health services, prescriptions, hospital discharges and length of hospital stay.

\section{Results}

Patients in geropsychiatric home treatment showed significantly lower numbers of consultations with general practitioners $(P<0.001)$ and specialists (internal medicine, $P=0.022$; psychiatry, $P<0.001$ ), and lower numbers of prescriptions (medical drugs except psychotropic drugs, $P<0.001$; psychotropic drugs, $P<0.004)$ compared with patients in treatment as usual. However, there was no significant difference in the number of hospital discharges and length of hospital stays.

\section{Conclusions}

Geropsychiatric home treatment has a positive effect on mental and physical parameters, which is discussed in the context of stress reduction.

\section{Keywords}

Mental illness; geropsychiatric home treatment; effectiveness; stress; physical health.

\section{Copyright and usage}

(c) The Author(s), 2021. Published by Cambridge University Press on behalf of the Royal College of Psychiatrists. This is an Open Access article, distributed under the terms of the Creative Commons Attribution-NonCommercial-ShareAlike licence (http://creativecommons.org/licenses/by-nc-sa/4.0/), which permits non-commercial re-use, distribution, and reproduction in any medium, provided the same Creative commons licence is included and the original work is properly cited. The written permission of Cambridge University Press must be obtained for commercial re-use.
The prevalence of mental disorders, mainly anxiety disorders and affective disorders, in older people is high: one in three older people were affected in the course of the past year. ${ }^{1}$ According to the World Health Organization, dementia is the leading cause of dependency and disability among older people. Dementia currently affects around 10 million people in Europe, and its prevalence is expected to double by $2030 .^{2}$

\section{Effects on mental health}

Several studies have examined the effectiveness of multidisciplinary home treatment models for elderly patients with mental illness. ${ }^{3}$ Data show significant positive effects on relevant parameters such as fewer symptoms of depression, ${ }^{4,5}$ an improvement in global and psychosocial functioning ${ }^{5,6}$ and better quality of life. ${ }^{5}$ Furthermore, the findings discussed by Klug et $\mathrm{al}^{5}$ indicate fewer admissions to nursing homes, fewer in-patient days spent in psychiatric hospitals and, subsequently, lower costs of care. Therefore, geropsychiatric home treatment (GHT) for elderly patients has been implemented in several parts of Austria. This treatment model includes social workers, psychiatric nurses, psychologists and psychiatrists, and offers an individually tailored home treatment for the patients in contrast to treatment as usual (TAU).

\section{Effects on physical health}

So, GHT has positive effects on older people in regard to mental health. But what about its effects on physical health? Studies indicate a relationship between physical and mental health in general, ${ }^{7-10}$ but specific studies in this field are scarce. Several authors refer to a significantly increased risk of chronic physical health problems in people with mental illness; ${ }^{11,12}$ Ohrnberger et $\mathrm{al}^{7,13}$ stated that little is known about the dynamic cross-effects between mental health and physical health. They found that the indirect effect of past mental health on physical health is mediated by lifestyle choices and social interactions. There is solid scientific evidence that social relationships affect a range of health outcomes, including mental health, physical health, health habits and mortality risk. ${ }^{14}$ People with mental illness are less likely to have protective relationships, and when their social links are poor, their recovery is compromised and they are at heightened risk of relapse. ${ }^{15}$ Furthermore, they are disadvantaged concerning recognition and treatment of physical health problems. ${ }^{9}$ Hummel et $\mathrm{al}^{16}$ demonstrated the effectiveness of cognitive-behavioural psychotherapy regarding improvement in physical and functional parameters in elderly patients. Callahan et $\mathrm{al}^{17}$ and Camacho et $\mathrm{al}^{18}$ discussed a collaborative care management for late-life depression and its association with improvement in physical functioning. Taking all these findings into account, we ask whether it is indeed possible that a focused GHT not only improves mental health, but can also reduce the need for physical treatment?

Thus, the aim of the present study was to examine the effect of this special GHT model on physical health for older people with mental illness, by the number of contacts with health services, number of prescriptions concerning medical drugs except 
psychotropic drugs as primary outcomes, number and length of hospital stays, number of prescriptions regarding psychotropic drugs and number of consultations with psychiatrists as secondary outcomes. It was hypothesised that patients in this particular treatment will have a significantly lower number of contacts with health services, prescriptions and hospital stays compared with patients receiving TAU.

\section{Method}

\section{Study design}

A data-based, retrospective matched-pair study was conducted to analyse the possible effects of the GHT model for the utilisation of medical care. Patients in GHT were allocated to the intervention group. For each patient in GHT, two statistically comparable patients in TAU were chosen by 1:2 matching and then allocated to the control group. Matched case-control study designs are commonly implemented in the field of public health and medical literature, ${ }^{19,20}$ for example, in cancer research ${ }^{21}$ and psychiatric research. $^{22,23}$

Data from the regional medical insurance company (RMIC) in Styria (a regional branch of the National Health Insurance in Austria) and data from the public hospitals in Styria were combined for both groups, and the patient pathways within 2016 were analysed for the statistical computing. The insurance data refer to the number of prescription drugs and the number of consultations with general practitioners (GPs) and extramural specialists in internal medicine and psychiatry, either panel doctors or private doctors of one's choice, whose bills are fully or partially paid by the health insurance in Austria.

Written informed consent was obtained from all participants despite only standardly compiled data being used; all data were pseudonymised. In this case, no ethics approval for the study was required from the ethics committee in Austria.

\section{Setting}

The study was conducted in Graz, the capital city of Styria, and in three rural regions in Styria, one of the nine states in Austria. At the beginning of 2016, about $18 \%$ of the 280000 inhabitants of Graz were aged $\geq 65$ years. The percentage was slightly higher in the three rural regions, with a total of approximately 228000 inhabitants.

All potential participants received full routine care within the Austrian healthcare system. The additional multi-professional treatment (GHT) was provided by the regional psychosocial services (PSS), i.e. three publicly funded, non-profit organisations specialising in mental health services in the community (Gesellschaft zur Förderung seelischer Gesundheit, Rettet das Kind Steiermark and Hilfswerk Steiermark). All psychiatric in-patient, out-patient and community services in the area could refer individuals to GHT.

The patients in the intervention group had to be in GHT in 2016 for at least 2 months, and had to be in active treatment between July and December.

\section{Intervention}

All participants in both conditions had free access to all aspects of healthcare as routinely provided by the Austrian healthcare system, including input from GPs, psychiatrists, day centres with social and occupational activities and, if required, nursing care in the individual's home. ${ }^{5}$

In addition to routinely provided care, patients in the intervention group received a GHT offered free of charge. First, a multiprofessional comprehensive geropsychiatric assessment ${ }^{24,25}$ and psychiatric interview ${ }^{26}$ took place. This assessment was carried out by a multi-professional team comprising a psychiatrist specialising in geriatric psychiatry and therefore familiar with somatic diseases in old age, psychologists, social workers and psychiatric nurses. However, in the rural regions, resources were partly limited to psychiatrists, psychologists and social workers. Subsequently, each patient in GHT was assigned to a primary keyworker who was one of the members of the multi-professional GHT team.

All team members specialised in dealing with the complex socio-psychiatric problems elderly people are confronted with. ${ }^{27}$ In accordance with Levin and Miya, ${ }^{28}$ the service (originally based on psychosocial rehabilitation) is highly individualised and focuses on recovery and strengths depending on the needs and resources of the patients. A detailed description of the setting has been published elsewhere. ${ }^{27}$

The cost-efficiency of GHT has already been proved in a previous study by Klug et al, ${ }^{5}$ therefore it was not assessed in the present study.

\section{Patient selection and matching}

Patients were referred to the intervention group if they met the following inclusion criteria:

a psychiatric diagnosis according to ICD-10 criteria, ${ }^{29}$ age $\geq 65$ years, main residence in one of the four regions, living independently at home, active treatment (GHT) between July and December of 2016 and treatment duration of at least 2 months.

Exclusion criteria were as follows: no informed consent, a score of $<23$ on the Mini-Mental State Examination, ${ }^{30}$ no regional medical insurance and an incomplete data-set (e.g. treatment duration $<2$ months, dropped out, relocated, indicated intention to give up independent living and move to a nursing home).

\section{Matching}

Patients for the control group were selected by 1:2 exact matching. For building the control group, the variables described above from the standardly compiled PSS data of all patients in the intervention group were transmitted to the RMIC, who identified potential controls from the standardly compiled data of all patients in Styria in 2016, using these matching criteria: no GHT in 2016, identical age in years, identical gender and identical residential area.

Next, the comparability of the control group was assured regarding psychiatric medication and the potential requirement of psychiatric care. For that to happen, the cohort was further limited by applying the following criteria: at least one consultation with a specialist in psychiatry in 2016, and prescriptions of psychotropic drugs in 2016 with at least one of these active ingredients: selective serotonin reuptake inhibitors, diazepine, oxazepine, thiazepine and oxepine, benzodiazepine derivates, other antidepressants and beta-adrenoreceptor antagonists.

Finally, each patient in the intervention group was matched with two statistically comparable people in the control group from the cohort of potentially comparable people with requirement of psychiatric care via computerised random sampling.

\section{Variables}

The following primary outcomes were analysed with descriptive and inferential statistics: number of consultations with GPs, number of consultations with specialists in internal medicine and number of prescriptions of medical drugs (excluding psychotropic drugs). The following secondary outcomes were analysed with descriptive and inferential statistics: number of consultations with specialists in psychiatry, number of prescriptions of psychotropic drugs, 
number of hospital discharges excluding psychiatric departments, number of hospital discharges in psychiatric departments and length of hospital stays.

\section{Data sources}

The software-controlled data analyses are based on standardly compiled patient and service data from the PSS, and standardly compiled data concerning patient characteristics, extramural consultation rates and the prescriptions extracted by the RMIC. In 2015 , about $74 \%$ of the Styrian residential population were insured by the RMIC. Thus, it is the biggest medical health insurance provider in Styria.

The analyses for hospital discharges and length of hospital stays are based on the standardly compiled patient, diagnosis and service data of the public hospitals in Austria.

The standardly compiled data of the PSS comprised the demographic variables (age, gender, residential area), medical insurance provider, initiation of treatment, main psychiatric diagnoses according to ICD-10 criteria, ${ }^{29}$ and the living conditions for all patients in the intervention group.

Concerning the RMIC data, demographic variables of the patients in the control group, and number of consultations (GPs and specialists) and prescriptions (including the Anatomic Therapeutic Chemical Code (ATC) of drugs) for all patients in the intervention and control group were used.

Data from the public hospitals comprised hospital discharges, length of stay, main diagnoses according to ICD-10 criteria, ${ }^{29}$ and full medical performance during the stay for all patients in the intervention and control group.

All data-sets were pseudonymised by a definite patient identifier to display the cross-sectoral healthcare pathways for 2016. For each patient, the individual care pattern was built, and the differences in the observed frequencies were statistically analysed.

\section{Study size}

The definition of the required study size and length of observation period was guided by the leading question: does the GHT model affect the number of contacts with GPs per year? The average consultation rate per year and inhabitant related to the entire population in Austria is about 13.7. ${ }^{31}$ It can be assumed that the number of consultations is higher in the $\geq 65$ years age group than in all other age groups.

On the basic assumptions of inferential statistics with a type 1 error of $5 \%$, a statistical power of $80 \%$ and an estimated effect size of $r=0.3$ (minimum difference of 3.6 consultations per patient and year between both groups - medium effect size because no comparable study has been carried out in Austria), at least 1219 consultations have to be observed in the intervention group and control group within a year for statistically significant results. Based on these conservative assumptions, a sample size of 89 was required.

\section{Statistical methods}

The results concerning the characteristics of patients and the observed frequencies were analysed for the intervention group (GHT) and control group (TAU) by means of descriptive and inferential statistics. The absolute frequencies and the percentage distributions were used for description of the nominal data.

The frequencies of the intervention group and control group are described as absolute frequencies per year, mean and median. The differences in frequency were analysed by Wilcoxon rank-sum test for independent samples at a 5\% significance level for a twotailed test. For all analyses, the statistics software R (version 3.5.3 for Windows; R Foundation for Statistical Computing) was applied.
The observed frequencies of the intervention and control groups are always related to the whole of 2016: out of 91 patients in the intervention group, 44 received continuous treatment in 2016 (48.4\%), 32 received treatment for half a year or more $(35.2 \%)$ and 15 received treatment for at least 2 months (16.4\%). For those, the observed frequencies of their individual active treatment period were considered and extrapolated to the absolute frequencies of a full year.

\section{Results}

\section{Patient flow}

A total of 482 patients were treated with GHT in 2016. A total of 91 patients met the inclusion criteria and were assigned to the intervention group. Figure 1 illustrates the patient flow and the 1:2 matching.

\section{Baseline characteristics of patients}

Age, gender and the residential area of the patients in the intervention group and control group are described in Table 1. The average age in both groups was 75.09 years (s.d. 6.0), and the majority of patients were female and from the Graz region. There were no differences in the baseline characteristics between the intervention group and control group because of the exact matching.

The primary diagnoses were assessed in detail according to ICD-10 criteria, ${ }^{29}$ and combined with homogenous diagnosis groups for patients in the intervention group: $38.4 \%$ had affective disorders (mainly F33 - recurrent depressive disorder and F32 depressive episode); $26.4 \%$ had a mild form of organic, including symptomatic, mental disorders (mainly F00 - dementia in Alzheimer's disease); $25.3 \%$ had neurotic, stress-related and somatoform disorders (mainly F41 - other anxiety disorders) and 9.9\% had other psychiatric diagnoses.

\section{Main results}

The observed frequencies and statistical values for the primary and secondary outcomes for the intervention group, as well as the control group, are shown in Table 2.

Thus, the number of consultations with GPs and specialists in internal medicine per patient in 2016 was significantly lower in the intervention group than the control group. The number of prescriptions of medical drugs except psychotropic drugs per patient in 2016 was also significantly lower than in the control group.

Regarding the secondary outcomes, the number of consultations with specialists in psychiatry per patient in 2016 was significantly lower in the intervention group than the control group. Also the number of prescriptions of psychotropic drugs per patient in 2016 was significantly lower in the intervention group.

The results concerning number of hospital discharges excluding psychiatric departments, and number of hospital discharges in psychiatric departments, show that there was no significant difference between the intervention and control groups. Scheduled hospital stays (e.g. day hospital, planned surgery, in-patient chemotherapy, etc.) were excluded to minimise bias in the results.

The length of hospital stays in days was also considered. In the intervention group, the median length of hospital stays was 2.5 days compared with 4.0 days in the control group. The difference between the groups was not statistically significant.

Table 2 shows significant differences for prescriptions concerning medical drugs except psychotropic drugs, as well as prescriptions concerning psychotropic drugs. Further, the number of prescriptions in both categories was examined in more detail by analysing the subgroups based on the ATC Classification System (second level, therapeutic subgroup). There was a significant 


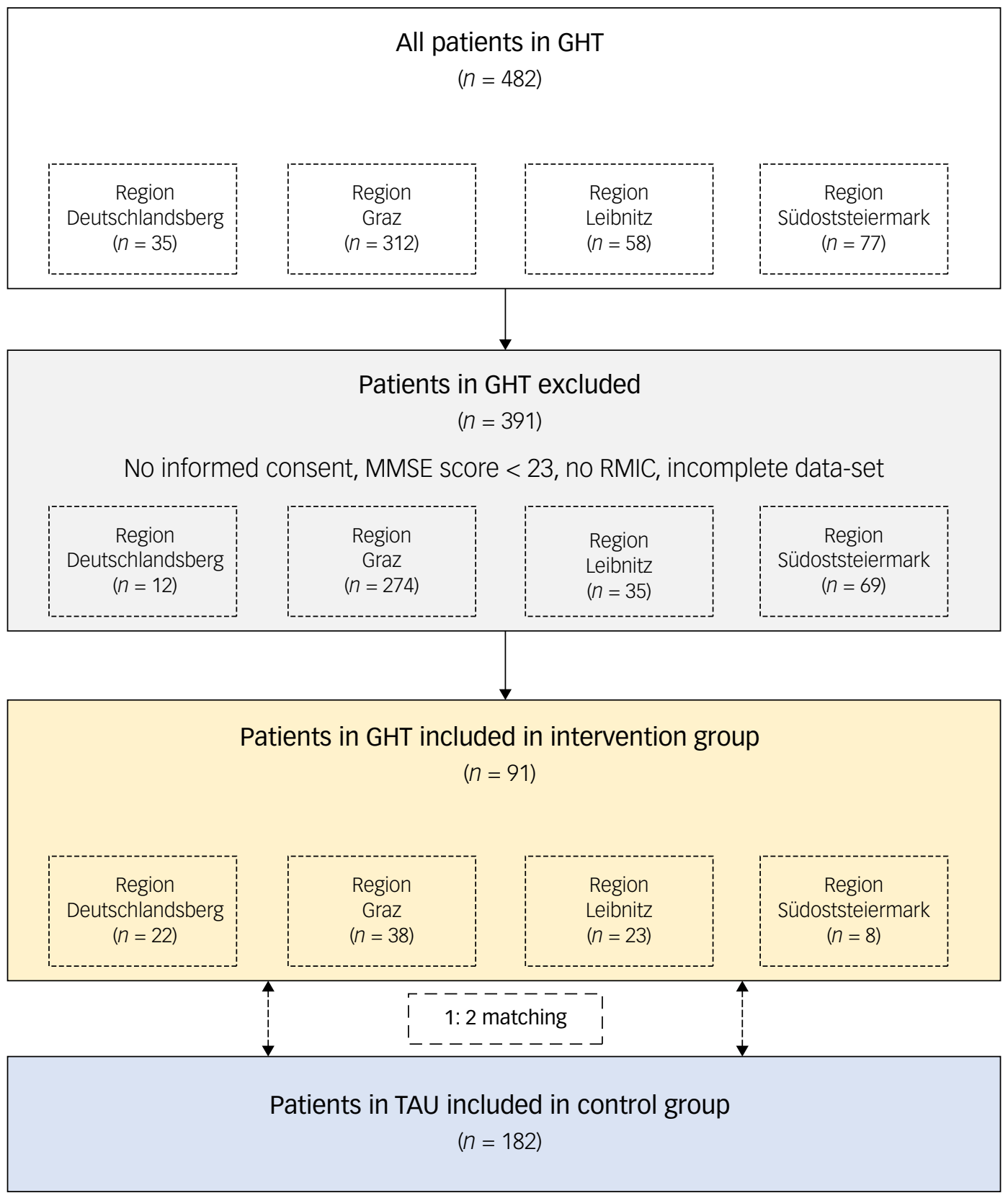

Fig. 1 Patient flow and matching. GHT, geropsychiatric home treatment; MMSE, Mini-Mental State Examination; RMIC, regional medical insurance company; TAU, treatment as usual.

difference for the ATC subgroups 'agents acting on the renin-angiotensin system' (C09) and 'psychoanaleptics' (N06) concerning the number of prescriptions for the intervention group. In almost every other subgroup there was also a lower number of prescriptions; however, the difference between the intervention group and control group was not significant.

The results for the top 15 prescriptions (ATC second level) are given in Table 3.

\section{Discussion}

\section{Main findings}

The present retrospective, matched-pair cohort study indicates that GHT has a positive effect on parameters of physical health in elderly patients. GHT was associated with a smaller number of consultations with health services (i.e. GPs, psychiatrists and other specialists) and prescription drugs. This not only refers to psychotropic drugs but is also true for non-psychotropic drugs.

However, the cohorts did not differ significantly concerning the number of general hospital discharges and the length of general hospital stays. There was also no significant difference concerning the number of psychiatric hospital discharges.

In view of the specified duration of the study and very small numbers of in-patients, it was difficult to prove statistically relevant changes for the number of hospital admissions alone.

The findings suggest that there was a change in the mental state and medical condition of the patients. The lower number of prescriptions in relation to consultations with GPs and psychiatrists can be partly explained by the better psychiatric care in the project itself. On the other hand, the lower number of consultations with GPs could also have led to the lower number of prescriptions, 
Table 1 Baseline characteristics of patients in the intervention group (geropsychiatric home treatment) and the control group (treatment as usual)

\begin{tabular}{|c|c|c|c|c|}
\hline & \multicolumn{2}{|c|}{$\begin{array}{l}\text { Intervention } \\
\text { group }(n=91)\end{array}$} & \multicolumn{2}{|c|}{$\begin{array}{l}\text { Control group } \\
\quad(n=182)\end{array}$} \\
\hline & $n$ & $\%$ & $n$ & $\%$ \\
\hline \multicolumn{5}{|l|}{ Gender } \\
\hline Male & 19 & 20.9 & 38 & 20.9 \\
\hline Female & 72 & 79.1 & 144 & 79.1 \\
\hline \multicolumn{5}{|l|}{ Age, years } \\
\hline $65-74$ & 44 & 48.4 & 88 & 48.4 \\
\hline $75-84$ & 43 & 47.3 & 86 & 47.3 \\
\hline$\geq 85$ & 4 & 4.4 & 8 & 4.4 \\
\hline \multicolumn{5}{|l|}{ Region } \\
\hline Graz & 38 & 41.8 & 76 & 41.8 \\
\hline Deutschlandsberg & 22 & 24.2 & 44 & 24.2 \\
\hline Leibnitz & 23 & 25.3 & 46 & 25.3 \\
\hline Südoststeiermark & 8 & 8.8 & 16 & 8.8 \\
\hline
\end{tabular}

as more frequent consultations with GPs most likely leads to more drug prescriptions. The high frequency of consultations with GPs in the control group compared with the intervention group could be an indicator of loneliness, missing social contacts and the GP often being the only contact person. However, the lower number of consultations with specialists in internal medicine, and especially the decrease in medication in the somatic and psychiatric areas, cannot be explained that way. The following fact is striking: the decrease in somatic medication is even stronger than the decrease in psychiatric medication. There was a slight (not significant) decrease in all somatic medication groups, but the largest decreases were in medications acting on the renin-angiotensin system, medications used for diabetes and acid-related disorders, and psychoanaleptics, including antidepressants. The decrease in antidepressants could be the result of GHT alone, but recent studies $^{32}$ show that the renin-angiotensin system and depression are strongly correlated. Although randomised controlled trials providing definitive proof are yet to come, there are indications of centrally powerful substances from the renin-angiotensin system having an effect on the treatment of depression. One reason for this is the triggering of a cascade of stress, especially chronic stress. This rebounds on the renin-angiotensin system, triggering psychiatric illnesses and having an altogether very harmful effect on the entire organism.

One might speculate that the efficacy of the treatment in GHT is in reducing the chronic stress levels of the patients across multiple pathways. That would align with our findings of a general slight decrease of all somatic medication, but mainly with the significant decrease of drugs targeting the renin-angiotensin system, depression, diabetes and acid-related disorders. Further studies that provide all of these data are needed to prove these assumptions.

The concept of GHT affects chronic stress in various ways. First, more intensive treatment results in faster medication adaptation. The resulting improvement in the condition and the easing of related anxieties reduces the general stress level. In addition, the frequent contacts and involvement of social work lead to a significant improvement in loneliness, as well as a better socioeconomic situation (which is currently rather unfavourable, especially for older women in Austria). Worries about physical condition, social and economic insecurity, and loneliness are each massive triggers of chronic stress. The relationships connected to GHT seem to have a stabilising effect on patients.

GHT can make a difference which could explain the elusive effect on psyche and physis. Future research in this direction is urgently required to provide more clarification about the mode of action.

\section{Comparison with the existing literature}

As confirmed in other studies, ${ }^{7,10,12}$ there is an association between mental and physical health. The bidirectional relationship between depression and hypertension is well known. ${ }^{33-35}$ Late-life depression is associated with a higher risk of both all-cause and cardiovascular mortality. ${ }^{36}$ Traumas in old age lead to psychiatric symptoms, mainly in the form of anxiety disorders, affective disorders and substance-related disorders, and to physical symptoms like chronic pain, greater frequency of hypertension and cardio-ischemic diseases. ${ }^{37,38}$ Clinically, multiple somatisation is more common than psychological symptoms. ${ }^{38,39}$ Effective factors (e.g. gate-keeper function, management in physical and mental multimorbidity) identified by Firth et $\mathrm{al}^{12}$ are considered in GHT. Moreover, older people benefit mentally and physically from frequent contact with health services ${ }^{40}$ in the form of therapeutic relationships, ${ }^{27}$ which was confirmed in the present study.

However, in contrast to other studies, ${ }^{5,41,42}$ there was no positive treatment effect concerning the number of hospital admissions and length of hospital stays, which might also be because of the very small number of in-patient cases, as mentioned above.

\section{Strengths and limitations of the study}

The main strength of this study is the comparability of data on psychiatric symptoms, general health and medication in GHT and TAU by using a large data-set from a national health insurance database.

Especially the cross-sectoral analysis of the patient behaviour of both groups enables a holistic view of the medical care for older

\begin{tabular}{|c|c|c|c|c|c|c|c|}
\hline & \multicolumn{3}{|c|}{ Intervention group $(n=91)$} & \multicolumn{4}{|c|}{ Control group $(n=182)$} \\
\hline & Number ${ }^{a}$ & Mean $^{b}$ & Median $^{\mathrm{b}}$ & Number $^{\mathrm{a}}$ & Mean $^{\mathrm{b}}$ & Median $^{\mathrm{b}}$ & $P$-value \\
\hline \multicolumn{8}{|l|}{ Primary outcomes } \\
\hline Consultations with general practitioners & 1876 & 20.6 & 18.0 & 5715 & 31.4 & 27.0 & $<0.001$ \\
\hline Consultations with specialists in internal medicine & 87 & 1.0 & 0.0 & 286 & 1.6 & 0.0 & 0.022 \\
\hline Prescriptions for medical drugs excluding psychotropic drugs & 4081 & 44.8 & 25.0 & 12338 & 67.8 & 49.5 & $<0.001$ \\
\hline \multicolumn{8}{|l|}{ Secondary outcomes } \\
\hline Consultations with specialists in psychiatry & 75 & 0.8 & 0.0 & 344 & 1.9 & 1.0 & $<0.001$ \\
\hline Prescriptions for psychotropic drugs & 1140 & 12.5 & 6.0 & 3756 & 20.6 & 1.0 & 0.004 \\
\hline Hospital discharges excluding psychiatric departments & 44 & 0.5 & 0.0 & 135 & 0.7 & 0.0 & 0.103 \\
\hline Hospital discharges in psychiatric departments & 15 & 0.2 & 0.0 & 12 & 0.1 & 0.0 & 0.973 \\
\hline Length of hospital stays (days) & 177 & 4.0 & 2.5 & 631 & 4.7 & 4.0 & 0.209 \\
\hline
\end{tabular}


Table 3 Top 15 prescriptions (ATC second level) results for the intervention group (geropsychiatric home treatment) and the control group (treatment as usual)

\begin{tabular}{|c|c|c|c|c|c|c|c|}
\hline & \multicolumn{3}{|c|}{ Intervention group $(n=91)$} & \multicolumn{4}{|c|}{ Control group $(n=182)$} \\
\hline & Number ${ }^{\mathrm{a}}$ & Mean $^{\mathrm{b}}$ & Median $^{\mathrm{b}}$ & Number ${ }^{\mathrm{a}}$ & Mean $^{\mathrm{b}}$ & Median $^{\mathrm{b}}$ & $P$-value \\
\hline \multicolumn{8}{|c|}{ Medical drugs except psychotropic drugs (ATC second level) subgroups } \\
\hline C09 - Agents acting on the renin-angiotensin system & 397 & 4.4 & 0.0 & 1307 & 7.2 & 3.0 & 0.0430 \\
\hline N02 - Analgesics & 329 & 3.6 & 0.0 & 1120 & 6.2 & 0.0 & 0.1900 \\
\hline A02 - Drugs for acid-related disorders & 350 & 3.9 & 0.0 & 970 & 5.3 & 2.0 & 0.1135 \\
\hline C10 - Lipid-modifying agents & 218 & 2.4 & 0.0 & 709 & 3.9 & 0.0 & 0.1289 \\
\hline B01 - Antithrombotic agents & 252 & 2.8 & 0.0 & 567 & 3.1 & 1.0 & 0.1112 \\
\hline c07 - Beta-blocking agents & 221 & 2.4 & 0.0 & 577 & 3.2 & 0.0 & 0.1629 \\
\hline C05 - Vasoprotectives & 147 & 1.6 & 0.0 & 538 & 3.0 & 0.0 & 0.6323 \\
\hline A12 - Mineral supplements & 199 & 2.2 & 0.0 & 450 & 2.5 & 0.0 & 0.6775 \\
\hline M02 - Topical products for joint and muscular pain & 98 & 1.1 & 0.0 & 471 & 2.6 & 0.0 & 0.7734 \\
\hline c08 - Calcium channel blockers & 186 & 2.0 & 0.0 & 365 & 2.0 & 0.0 & 0.7684 \\
\hline A10 - Drugs used in diabetes & 83 & 0.9 & 0.0 & 436 & 2.4 & 0.0 & 0.2111 \\
\hline C03 - Diuretics & 128 & 1.4 & 0.0 & 291 & 1.6 & 0.0 & 0.6064 \\
\hline \multicolumn{8}{|l|}{ Psychotropic drugs (ATC second level) subgroups } \\
\hline N06 - Psychoanaleptics & 688 & 7.6 & 4.0 & 2060 & 11.3 & 10.0 & $<0.001$ \\
\hline N05 - Psycholeptics & 451 & 5.0 & 0.0 & 1679 & 9.2 & 0.0 & 0.1626 \\
\hline N03 Anti-epileptics ${ }^{c}$ & 108 & 1.2 & 0.0 & 387 & 2.1 & 0.0 & 0.5663 \\
\hline \multicolumn{8}{|c|}{$\begin{array}{l}\text { ATC, Anatomic Therapeutic Chemical Code. } \\
\text { a. 'Number' refers to a whole year and to all patients ( } 91 \text { and } 182 \text {, respectively). } \\
\text { b. 'Mean'and 'Median' are given for the individual patient. } \\
\text { c. Anti-epileptics are included in both categories. }\end{array}$} \\
\hline
\end{tabular}

people with mental illness. This approach encompasses intra- and extramural care, as well as the entire medical treatment for this group of patients. A further strength refers to the fact that there are only a few studies trying to link physical health and the effectiveness of a psychiatric treatment model.

This study has several limitations that should be taken into consideration. First, there was a difference in the team settings concerning urban and rural regions because of the non- availability of special occupational groups in the rural regions.

A certain limitation is the small case number concerning specialists and hospital stays.

The statistical projection for those patients in the intervention group who did not have a continuous treatment with GHT in the whole of 2016 might also be a limitation.

Finally, concerning matching, future studies might also want to consider further important variables such as mental and physical health status in the pre-study period.

\section{Implications}

The present study demonstrates a direct link between a multi-professional out-patient psychosocial treatment and physical health. To our knowledge, this is one of the first studies in this particular field.

The outstanding feature of GHT is the very individual and target-oriented treatment and support compared with usual treatment models. All therapies and social support are coordinated regarding content and time, and the effectiveness is continuously evaluated by the team members. The changes in prescription behaviour (reduction in quantity and type; polypharmacy) have a high potential to positively influence general health. In this way, possible side-effects and adverse effects of medicinal long-term therapies can be minimised. However, in this context it should be mentioned that although polypharmacy is undoubtedly a frequent problem in the elderly, undertreatment with regard to indicated drugs may be observed as well (see also O’Mahony et $\mathrm{al}^{43}$ ).

GHT seems to reduce chronic stress levels. It certainly needs further studies, with larger sample sizes and longer observation periods, to confirm the findings of the present study.

There is also a need to explore differences in effects depending on the diagnosis and severity of the disease.
The complexity of the relationships between health factors underlines the need for complex interventions and increased implementation of psychosocial treatments like GHT. Overall, GHT has great potential to improve both mental and physical parameters.

Christa Peinhaupt, Institute for Health Care Strategies, Austria; Gernot Fassolder, Institute for Health Care Strategies, Austria; Wolfgang Habacher, Institute for Health Care Strategies, Austria; Monika Singer, Department of Social Psychiatric Help in Old Age, Society for Mental Health Promotion, Austria; Gerhard Hermann, Department of Social Psychiatric Help in Old Age, Society for Mental Health Promotion, Austria; Günter Klug (DD, Society for Mental Health Promotion, Medical University of Graz, Austria

Correspondence: Günter Klug. Email: guenter.klug@gfsg.at

First received 11 Nov 2020, final revision 21 Jul 2021, accepted 7 Aug 2021

\section{Funding}

This study was funded by the Health Care Funds of Styria. The funder had no role in conducting the study.

\section{Acknowledgements}

We would like to thank the Health Care Funds of Styria and the Austrian Health Insurance Company - RMIC for help with data retrieval; and all colleagues at the PSS Gesellschaft zur Förderung seelischer Gesundheit GmbH, Rettet das Kind Steiermark and Hilfswerk Steiermark, for help with data collection. We also thank Professor Stefan Priebe (Unit for Social and Community Psychiatry, Queen Mary University of London) for his valuable comments on the manuscript.

\section{Data availability}

Single data-sets were made available by the Social Insurance Company, Health Care Funds of Styria and PSS; the cross-sectoral data were made available by the Institute for Health Care Strategies (guaranteed data destruction at the end of the project - official requirement to destroy the Social Insurance data). Data is available only upon new request by the data holders.

\section{Author contributions}

C.P. contributed to the conception and design of the study, project management, analysis and interpretation of the data, and drafting the manuscript. G.F. contributed to the conception and design of the study, analysis and interpretation of the data, and drafting the manuscript. W.H. contributed to the conception and design of the study, and drafting the manuscript. M.S. and G.H. contributed to scientific counselling, interpretation of the data, and drafting and revising the manuscript. G.K. contributed to scientific counselling, supervising data collection, interpretation of the data, and drafting and revising the manuscript. All authors have approved the final version of the manuscript. 


\section{Declaration of interest}

None.

\section{References}

1 Andreas S, Schulz H, Volkert J, Dehoust M, Sehner S, Suling A, et al. Prevalence of mental disorders in elderly people: the European MentDis_ICF65+ study. Br J Psychiatry 2017; 210(2): 125-31.

2 World Health Organization. Towards a Dementia Plan: A WHO Guide. World Health Organization, 2018 (https://apps.who.int/iris/bitstream/handle/10665/ 272642/9789241514132-eng.pdf?ua=1).

3 Klug G, Gallunder M, Hermann G, Singer M, Schulter G. Effectiveness of multidisciplinary psychiatric home treatment for elderly patients with mental illness: a systematic review of empirical studies. BMC Psychiatry 2019; 19: 382-94.

4 Banerjee S, Shamash K, Macdonald AJD, Mann AH. Randomised controlled trial of effect of intervention by psychogeriatric team on depression in frail elderly people at home. BMJ 1996; 313: 1058-61.

5 Klug G, Hermann G, Fuchs-Nieder B, Panzer M, Haider-Stipacek A, Zapotoczky $\mathrm{HG}$, et al. Effectiveness of home treatment for elderly people with depression: randomised controlled trial. Br J Psychiatry 2010; 197(6): 463-7.

6 Stobbe J, Wierdsma Al, Kok RM, Kroon H, Roosenschoon BJ, Depla M, et al. The effectiveness of assertive community treatment for elderly patients with severe mental illness: a randomized controlled trial. BMC Psychiatry 2014; 14: 42 .

7 Ohrnberger J, Fichera E, Sutton M. The dynamics of physical and mental health in the older population. J Econ Ageing 2017; 9: 52-62.

8 Jolley D, Kosky N, Holloway F. Older people with long-standing mental illness: the graduates. Adv Psychiatr Treat 2004; 10: 27-34.

9 Coghlan R, Lawrence D, Holman CD, Jablensky AV. Duty to Care: Physical IIIness in People with Mental IIIness. The University of Western Australia, 2001 (http:// www.wanada.org.au/index.php?option=com_docman\&view=document\&layout=default\&alias=48-duty-to-care-physical-illness-in-people-with-mental-illness\&category_slug=healthy-eating-and-wellbeing-guides\&ltemid=265).

10 Kisely SR, Goldberg DP. The effect of physical ill health on the course of psychiatric disorder in general practice. Br J Psychiatry 1997; 170: 536-40.

11 Park A, McDaid D, Weiser P, Von Gottberg C, Becker T, Kilian T. Examining the cost effectiveness of interventions to promote the physical health of people with mental health problems: a systematic review. BMC Public Health 2013; 13: 787.

12 Firth J, Siddiqi N, Koyanagi A, Siskind D, Rosenbaum S, Galletly C, et al. The Lancet Psychiatry Commission: a blueprint for protecting physical health in people with mental illness. Lancet Psychiatry 2019; 6(8): 675-712.

13 Ohrnberger J, Fichera E, Sutton M. The relationship between physical and mental health: a mediation analysis. Soc Sci Med 2017; 195: 42-9.

14 Umberson D, Montez JK. Social relationships and health: a flashpoint for health policy. J Health Soc Behav 2011; 51(suppl): S54-66.

15 Pevalin DJ, Goldberg DP. Social precursors to onset and recovery from episodes of common mental illness. Psychol Med 2003; 33(2): 299-306.

16 Hummel J, Weisbrod C, Boesch L, Himpler K, Hauer K, Hautzinger M, et al. AIDEacute illness and depression in elderly patients. Cognitive behavioral group psychotherapy in geriatric patients with comorbid depression: a randomized, controlled trial. J Am Med Dir Assoc 2017; 18(4): 341-9.

17 Callahan CM, Kroenke K, Counsell SR, Hendrie HC, Perkins AJ, Katon W, et al. IMPACT investigators. treatment of depression improves physical functioning in older adults. J Am Geriatr Soc 2005; 53(3): 367-73.

18 Camacho EM, Davies LM, Hann M, Small N, Bower P, Chew-Graham C, et al. Long-term clinical and cost-effectiveness of collaborative care (versus usual care) for people with mental-physical multimorbidity: cluster-randomised trial. Br J Psychiatry 2018; 213(2): 456-63.

19 Rose S, van der Laan MJ. Why match? Investigating matched case-control study designs with causal effect estimation. Int J Biostat 2009; 5(1): 1-24.

20 Burden A, Roche N, Miglio C, Hillyer EV, Postma DS, Herings RMC, et al. An evaluation of exact matching and propensity score methods as applied in a comparative effectiveness study of inhaled corticosteroids in asthma. Pragmat Obs Res 2017; 8: 15-30.

21 Ishikawa H, Yasunaga H, Matsui H, Fushimi K, Kawakami N. Differences in cancer stage, treatment and in-hospital mortality between patients with and without schizophrenia: retrospective matched-pair cohort study. $\mathrm{Br} J$ Psychiatry 2016; 208(3): 239-44.

22 Osimo EF, Brugger SP, De Marvao A, Pillinger T, whitehurst T, Statton B, et al. Cardiac structure and function in schizophrenia: cardiac magnetic resonance imaging study. Br J Psychiatry 2020; 217(2): 450-7.

23 Fond G, Pauly V, Bege T, Orleans V, Braunstein D, Leone M, et al. Trauma-related mortality of patients with severe psychiatric disorders: population-based study from the French national hospital database. Br J Psychiatry 2020; 217(4): 568-74.

24 Pinto C. The geropsychiatric interview, assessment and diagnosis. In Geriatric Psychiatry. Clinical Practice Guidelines (eds S Gautam, A Awasthi): 235-57. Indian Psychiatric Society, 2007.

25 Reuben DB. Comprehensive Geriatric Assessment and Systems Approaches to Geriatric Care. Geriatric Medicine. Springer Publishing, 2003.

26 Varghese $M$, Dahale AB. The geropsychiatric interview- assessment and diagnosis. Indian J Psychiatry 2018; 60(3): S301-11.

27 Klug G, Hermann G, Fuchs-Nieder B, Stipacek A, Zapotoczky HG. Geriatric psychiatry home treatment (GHT): a pilot study on outcomes following hospital discharge for depressive and delusional patients. Arch Gerontol Geriatr 2008; 47(1): 109-20.

28 Levin S, Miya K. Assertive community treatment for older adults. Psychiatr Serv 2008; 59(1): 113.

29 World Health Organization. The ICD-10 Classification of Mental and Behavioural Disorders: Diagnostic Criteria for Research (2nd edn). World Health Organization, 2003 (https://www.who.int/classifications/icd/en/bluebook.pdf).

30 Felnhofer A, Kothgassner O, Kryspin-Exner I. Consent capacity in dementia: sensitivity of MMSE in a hypothetical consent situation and specific cognitive correlates. Z Neuropsychol 2013; 24: 267-75.

31 Hofmarcher MM. Das österreichische Gesundheitssystem - Akteure, Daten, Analysen [The Austrian health care system - actors, data, analyses]. Medizinisch wissenschaftliche Verlagsgesellschaft, 2013 (https://broschuerenservice.sozialministerium.at/Home/Download?publicationld=545).

32 Vian J, Pereira C, Chavarria V, Köhler C, Stubbs B, Quevedo J, et al. The reninangiotensin system: a possible new target for depression. BMC Med 2017; 15: 144.

33 Goldstein BI, Carnethon MR, Matthews KA, McIntyre RS, Miller GE, Raghuveer G, et al. Major depressive disorder and bipolar disorder predispose youth to accelerated atherosclerosis and early cardiovascular disease: a scientific statement from the American Heart Association. Circulation 2015; 132: 965-86.

34 Johansen A, Holmen J, Stewart R, Bjerkeset O. Anxiety and depression symptoms in arterial hypertension: the influence of antihypertensive treatment. the HUNT study, Norway. Eur J Epidemiol 2012; 27: 63-72.

35 Meng L, Chen D, Yang $Y$, Zheng $Y$, Rutai $H$. Depression increases the risk of hypertension incidence: a meta-analysis of prospective cohort studies. J Hypertens 2012; 30(5): 842-51.

36 Wei J, Hou R, Zhang X, Xu H, Xie L, Chandrasekar EK, et al. The association of late-life depression with all-cause and cardiovascular mortality among community-dwelling older adults: systematic review and meta-analysis. Br J Psychiatry 2019; 215(2): 449-55.

37 Chaudieu I, Norton J, Ritchie K, Birmes P, Vaiva G, Anselin ML. Late-life health consequences of exposure to trauma in a general elderly population: the mediating role of reexperiencing posttraumatic symptoms. J Clin Psychiatry 2011; 72(7): 929-35.

38 Kütemeyer M. Normopathie - hypersoziale Traumaverarbeitung und somatoforme Dissoziation [Normopathy - hypersocial trauma reprocessing and somatoform dissociation]. Psychotherapie im Alter 2007; 1(4): 39-53.

39 Al Busaidi ZQ. The concept of somatisation. SQU Med J 2010; 10(2): 180-6.

40 Troya MI, Babatunde O, Polidano K, Bartlam B, McCloskey E, Dikomitis L, et al. Selfharm in older adults: systematic review. Br J Psychiatry 2019; 214(4): 186-200.

41 Vulser $\mathrm{H}$, Vinant V, Lanvin V, Chatellier G. Association between the timing of consultation-liaison psychiatry interventions and the length of stay in general hospital. Br J Psychiatry 2021; 218(4): 204-9.

42 Stulz N, Wyder L, Maeck L, Hilpert M, Lerzer H, Zander E, et al. Home treatment for acute mental healthcare: randomised controlled trial. Br J Psychiatry 2020; 216(6): 323-30.

43 O'Mahony D, O'Sullivan D, Byrne S, O'Connor MN, Ryan C, Gallagher P. STOPP/ START criteria for potentially inappropriate prescribing in older people: version 2. Age Ageing 2014; 44: 213-8. 